\title{
MULTI USER PERFORMANCE ON MC CDMA SINGLE RELAY COOPERATIVE SYSTEM BY DISTRIBUTED STBC IN RAYLEIGH FADING CHANNEL
}

\author{
Gelar Budiman, Ali Muayyadi and Rina Pudji Astuti \\ Electrical Engineering Faculty, Telkom University, Bandung, Indonesia
}

\begin{abstract}
Increasing data rate and high performance is the target focus of wireless communication. The multi carrier on multi-hop communication system using relay's diversity technique which is supported by a reliable coding is a system that may give high performance.

This research is developing a model of multi user and two scheme of multi carrier CDMA on multi hop communication system with diversity technique which is using Alamouti codes in Rayleigh fading channel. By Alamouti research, Space Time Block Code (STBC) for MIMO system can perform high quality signal at the receiver in the Rayleigh fading channel and the noisy system. In this research, MIMO by STBC is applied to single antenna system (Distributed-STBC/DSTBC) with multi carrier CDMA on multi hop wireless communication system (relay diversity) which is able to improve the received signal performance.

MC DS CDMA on multi hop wireless communication system with 2 hops is better performing than MC CDMA on multi user without Multi User Detector. To reach BER 10-3 multi hop system with MC CDMA needs more power $5 \mathrm{~dB}$ than MC DS CDMA at 5 users using Alamouti scheme for symbol transmission at the relay.
\end{abstract}

\section{Keywords :}

Alamouti, MIMO, multi user, Multi Carrier, CDMA, MC CDMA, MC DS CDMA, Distributed$S T B C / D S T B C$, diversity, Rayleigh fading, multi-hop system, relay's diversity

\section{INTRODUCTION}

Wireless communication system development nowadays focused to support the services with high data rate for some the contents of multimedia such as sound, images, data and video. Moreover, the transmitted data is expected to have the better quality with a low bit error rate. To provide the interactive multimedia services, it needs a large bandwidth. However, the available bandwidth is limited, and the wireless communication system has more complex channel characteristic than wireline.

To improve the performance of the wireless system, there should be improvement of coding scheme in the transmitter and receiver. One of them is to apply the code block in multi antenna systems, known as Multiple Input Multiple Output (MIMO). One of MIMO transmission 
techniques often used is Space Time Block Code (STBC) found by Siavash M. Alamouti [1]. STBC is a such technique that relies on code orthogonality, so the correlation between the antennas would be very small and has an impact to perform better quality than the system without using STBC [1].

The application of STBC was not only good for the multi-antenna system or MIMO, but also the application of STBC in the cooperative communications with multi hop can improve the system transmission performance significantly even with single-antenna [2]. The application of STBC cooperative communications is called the Distributed-STBC (DSTBC). In this research, DSTBC applied to cooperative communication with single antenna on the Rayleigh fading channels and used 2 hops for the simulation. The model of system uses MC CDMA as the modulation. This research also analyzes the affect of user number to the system performance.

\section{BASIC THEORY}

\subsection{Multi Input Multi Output (MIMO) Overview}

MIMO system is a transmission system (Tx-Rx) where the number of antenna either transmitter or receiver consists of several antenna. Many coding scheme has been performed at MIMO system to get better received signal quality. Alamouti codes is one of the coding scheme to apply at MIMO system which perform good quality.

Orthogonal space time block code is transmission scheme introduced by Alamouti. Alamouti has introduced coding scheme for $2 \times 2$ or $2 \times 1$ antenna which is shown at figure 1 [6].

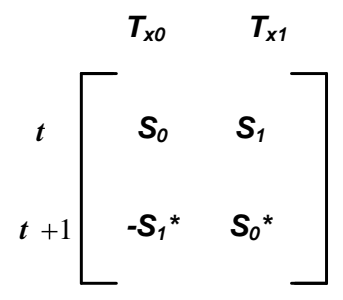

Figure 1: Orthogonal Space Time Block Code transmission scheme [1]

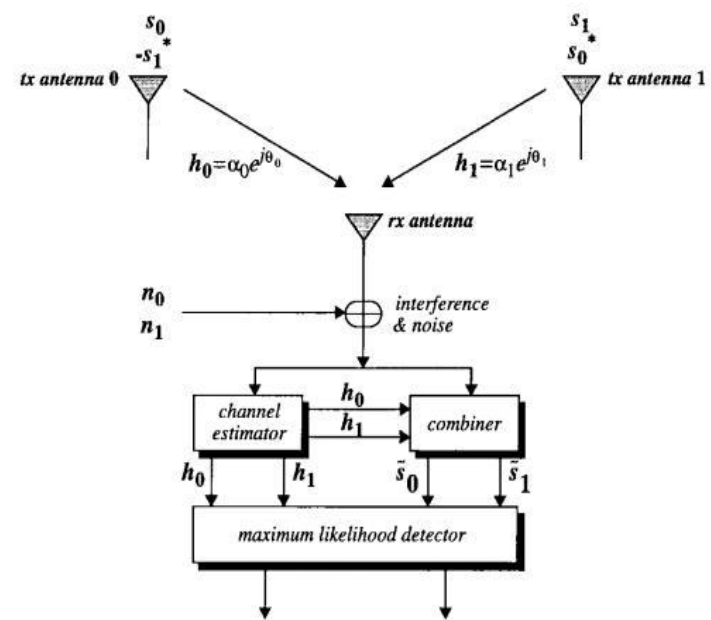

Figure 2 : MIMO scheme with 2 Tx Antenna and 1 Rx Antenna (2x1) [1] 


\subsection{Diversity by Distributed Space Time Block Code (DSTBC)}

The application of STBC was not only good for the multi-antenna system or MIMO, but also for cooperative communications with multi hop system. It can improve the system transmission performance significantly even with single-antenna [2]. The application of STBC cooperative communication is called the Distributed-STBC (DSTBC). The system scenario is described as the situation displayed in figure 3 .

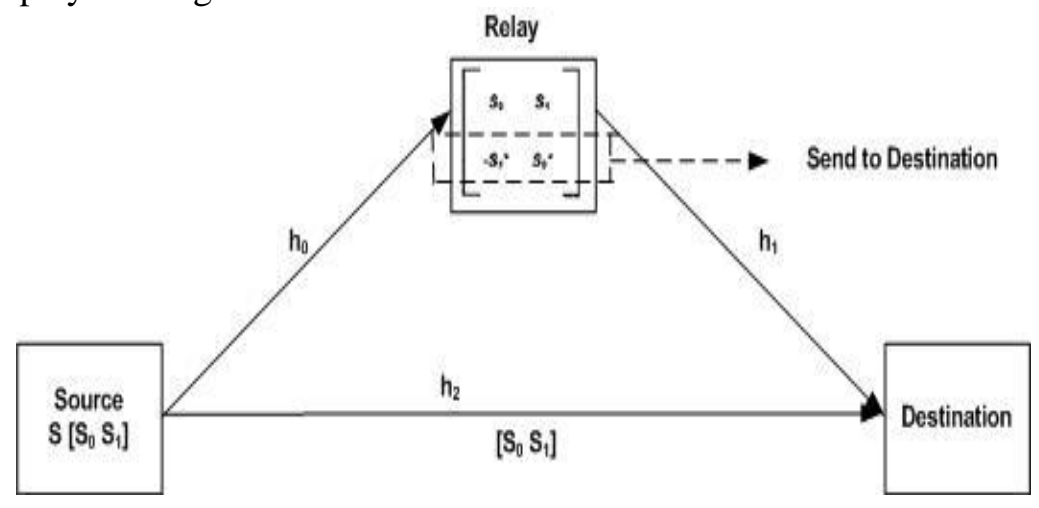

Figure 3 : Transmission scheme based of relay technique [3] [4]

According to figure 3 , the equation of received signal is :

$$
\begin{gathered}
r_{1}=-s_{2}^{*} h_{1}+s_{1} h_{2} \\
r_{2}=s_{1}^{*} h_{2}+s_{2} h_{3}
\end{gathered}
$$

Combiner block in figure 3 makes two signals below which will be transmitted to maximum likelihood detector :

$$
\begin{array}{r}
s_{1}=r_{1} h_{3}^{*}+h_{2} r_{2}^{*} \\
s_{2}=-h_{2} r_{1}^{*}+h_{3} r_{2}^{*}
\end{array}
$$

\subsection{Transmission Channel Decoding}

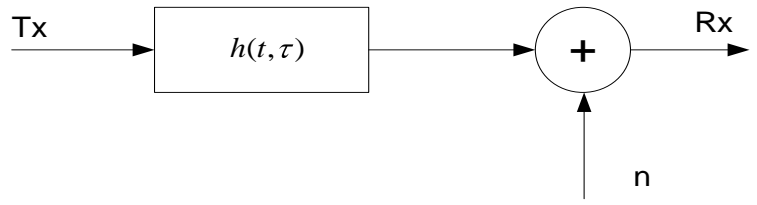

Figure 4 : General Channel Model [5]

A transmission channel generally can be defined:

$h(t, \tau)$ is time varying impulse response from multipath channel, mathematically it's defined as [5]: 


$$
\begin{aligned}
& h t, \tau=\sum_{i=0}^{N-1} a_{i} t, \tau_{i} t \quad p t, \tau_{i} t \\
& p t, \tau_{i} t=\mathrm{e}^{j 2 \pi f_{c} \tau_{i} t+\theta t, \tau_{i} t} \delta t-\tau_{i} t
\end{aligned}
$$

where:

- $\quad a_{i} \boldsymbol{(} \tau_{i}(t)$ is gain from $i$-th multipath component at time $t$.

- $2 \pi f_{c} \tau_{i} \bigcirc \theta_{i}\left(\tau_{i}(t)\right.$ is a term to representate phase shifting because of propagation at $i$ th multipath component.

- $\quad N$ is propagation path number.

Doppler shifting is expressed by equation [2]:

$$
f_{d}=\frac{v}{\lambda} \cos \theta
$$

where :

$v=$ relative movement velocity

$\lambda=$ wavelength of carrier

$\theta=$ angle between incoming signal direction and antenna movement direction

\subsection{Multicarrier Modulation}

Multicarrier modulation is defined as modulation technique in which there are several subcarrier or frequency to modulate the separate signal and every subcarrier is orthogonal each other. This mechanism is also called OFDM (Orthogonal Frequency Division Multiplexing). By this nature the signal in every subcarrier can be overlapped without Intercarrier Interference (ICI). This mechanism can save bandwitdh needs [9]. Spectrum illustration between conventional FDM and multicarrier (OFDM) is shown at figure 5.

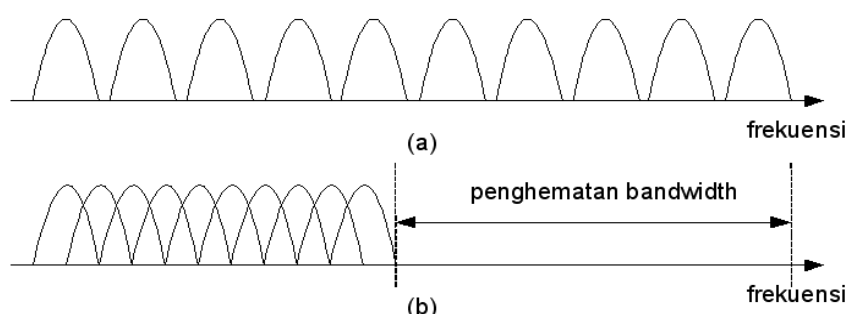

(b)

Figure 5 : Multi Carrier Spectrum (a) No Overlap (b) Orthogonally Overlap

Mathematically, group of signal $\varphi_{\mathrm{i}}, \mathrm{i}= \pm 0, \pm 1, \pm 2, \ldots$., akan ortogonal pada interval $[\mathrm{a} b]$, jika :

$$
\begin{gathered}
\int_{a}^{b} \varphi_{l}(t) \varphi_{k}^{*}(t) d t= \begin{cases}E_{k}, & \text { jika } l=k \\
0, & \text { jika } l \neq k\end{cases} \\
=E_{k} \delta(l-k)
\end{gathered}
$$


$E_{k}$ is constant resulting from integration and $\varphi_{k}^{*}(\mathrm{t})$ is conjugate complex from signal $\delta(l-k)$ (delta kronecker) [10], which is defined as :

$$
\delta(l-k)= \begin{cases}1, & \text { when } l=k \\ 0, & \text { when } l \neq k\end{cases}
$$

Basis function Discrete Fourier Transform (DFT) or Fast Fourier Transform is : $\varphi_{k}(t)=e^{\mathbf{I}(2 \pi k t) / T_{-}^{-}}$, where $\mathrm{k}=0, \pm 1, \pm 2, \pm 3, \ldots \ldots$ forms group of orthogonal signal at interval $(0$, T) $(T=$ signal periode $)$ :

$$
\begin{aligned}
\int_{0}^{T} \phi_{l}(t) \varphi_{k}^{*}(t) d t & =\int_{0}^{T} \exp \left[\frac{j(2 \pi l t)}{T}\right] \exp \left[\frac{-j(2 \pi k t)}{T}\right] d t \\
& = \begin{cases}T, & j i k a l=k \\
0, & j i k a l \neq k\end{cases}
\end{aligned}
$$

\section{COOPERATIVE SYSTEM BASED ON ONE RELAY MODEL (2 HOPS SYSTEM)}

\subsection{Model System}

The communication between the source and the user not only directly but also through the relay. So that, the received signal is the sum of the user that sent the signal directly (direct channel) and signal through the relay (the relay channel).

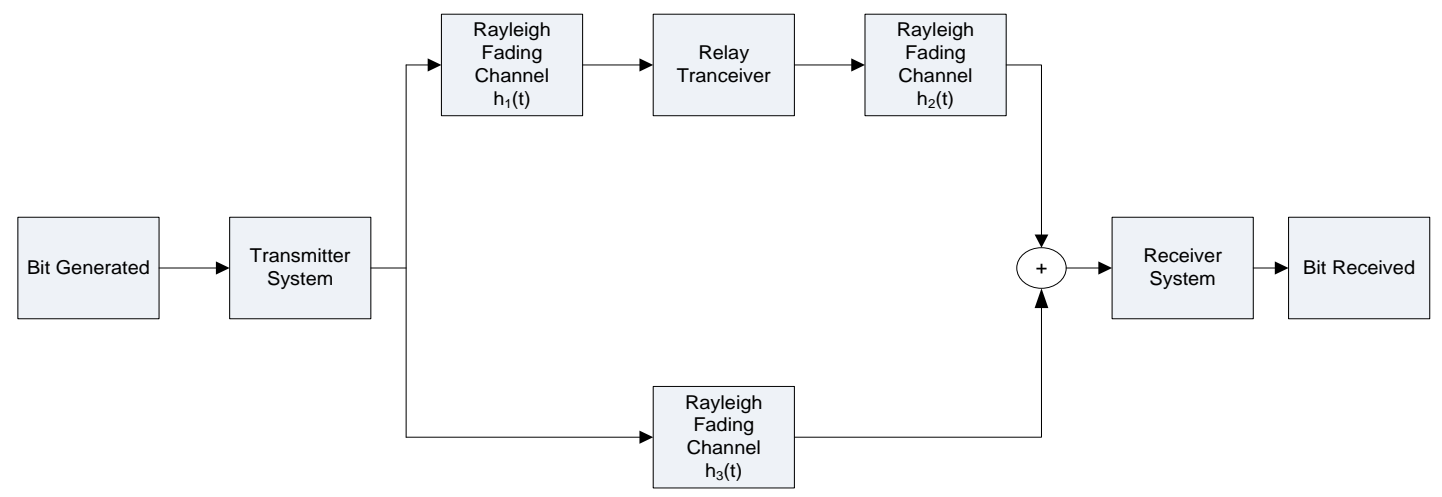

Figure 6 : Two Hops System Model with Single Antenna [9]

As shown at figure 6 the multi hop system introduced 2 hops, such as : 1 . the hop between base station (BS) and mobile station (MS) via relay, 2. the hop between BS and mobile station (MS) directly without relay. Fading channel distribution realized in 2 hops are Rayleigh fading channel in i.i.d distributed. Because of Rayleigh channel, received signal performance of 2 hops system should be affected by mobility of either relay or MS velocity. Figure 7 explained SISO (Single Input Single Output) system model (1 hop system) in which its performance will be compared to 2 hops system performance [9]. 
International Journal of Computer Networks \& Communications (IJCNC) Vol.7, No.1, January 2015

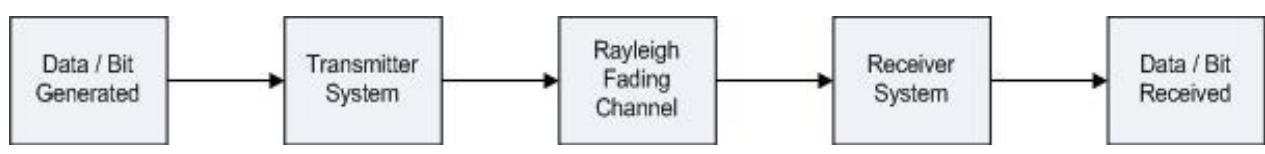

Figure 7 : SISO System Model [7]

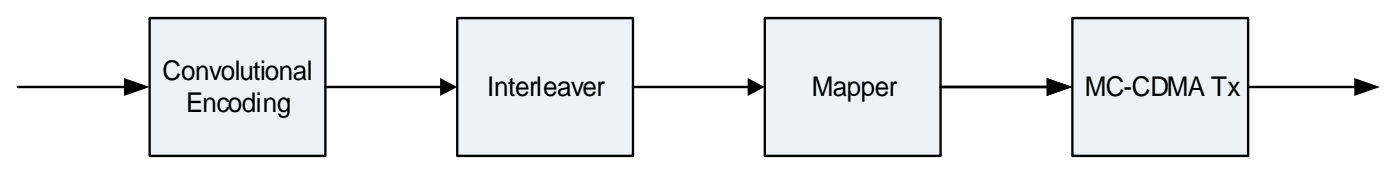

Figure 8 : Transmitter System Model

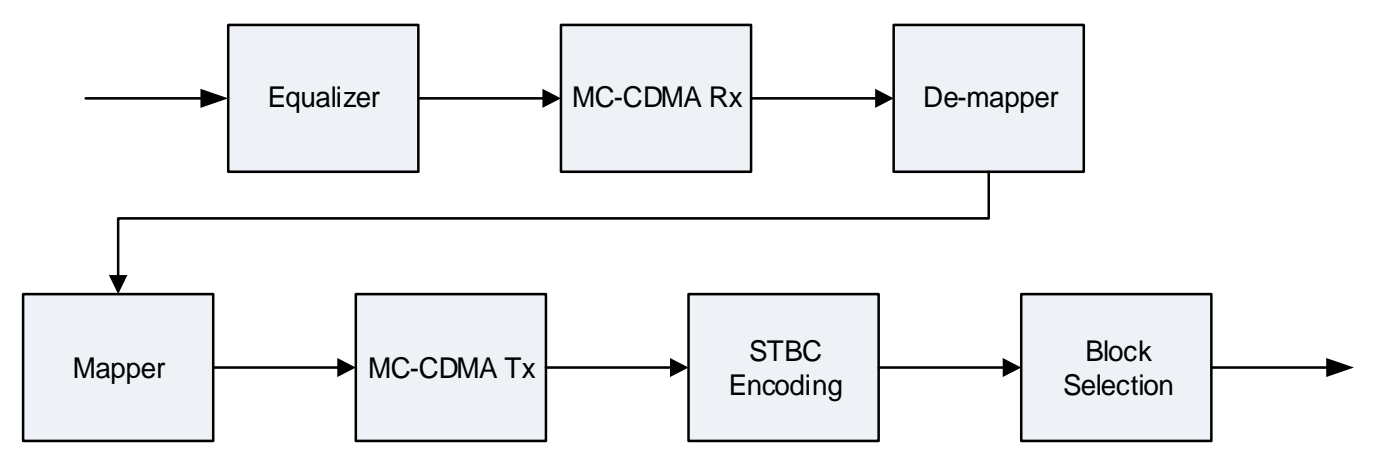

Figure 9 : Relay Tranceiver System Model [9]

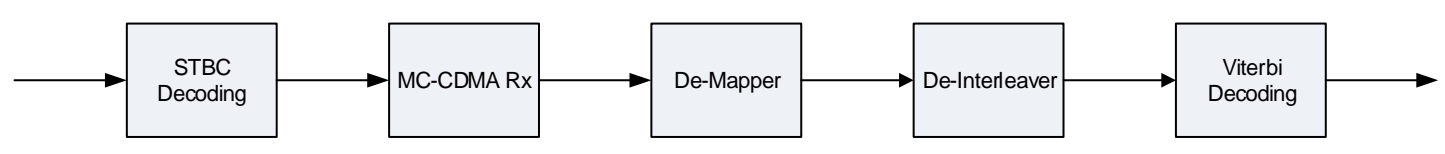

Figure 10 : Receiver System Model

The transmitter system of BS or SISO transmitter consists of 3 subsystems processing baseband signal as shown in figure 8. While relay transceiver from figure 6 consists of 5 subsystems which equalized, normalized, STBC encoded, and selected one block code before transmitting the signal to MS as shown in figure 9. As shown in figure 10, receiver system consists of several subsystem which decoded combined signal from BS and relay by Alamouti principal, demodulate, deinterleave, and Viterbi decoded. Next, the data compared to the original data for counting BER performance.

The content of MC CDMA transmitter by frequency domain spreading is shown in figure 11. The content of MC CDMA receiver by frequency domain spreading is shown in figure 12 .

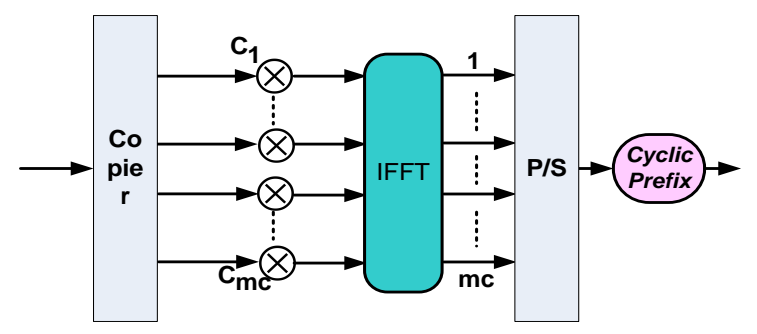

Figure 11 : MC CDMA Transmitter Model System [7] 


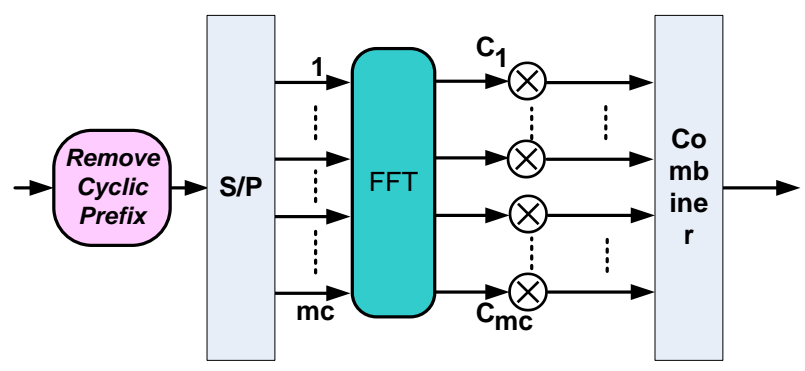

Figure 12 : MC CDMA Receiver Model System [7]

The content of MC DS CDMA transmitter by frequency domain spreading is shown in figure 13. The content of MC Ds CDMA receiver by time domain spreading is shown in figure 14 .

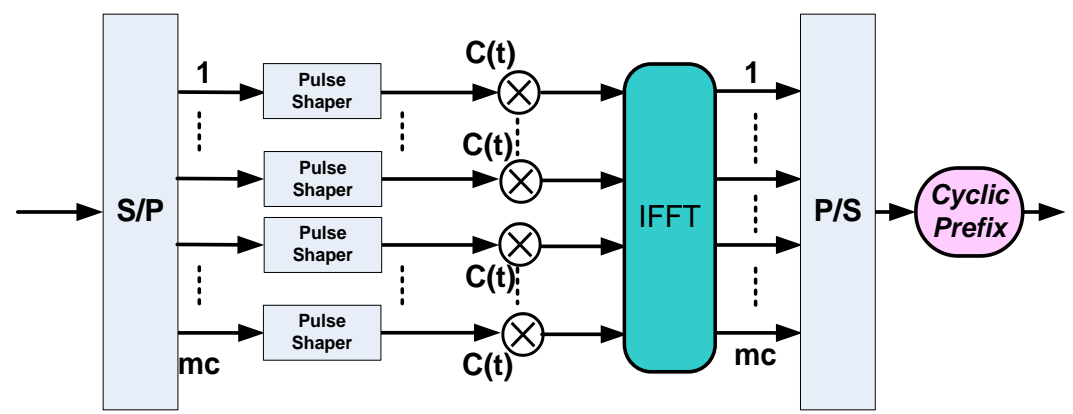

Figure 13 : MC DS CDMA Receiver Model System [7]

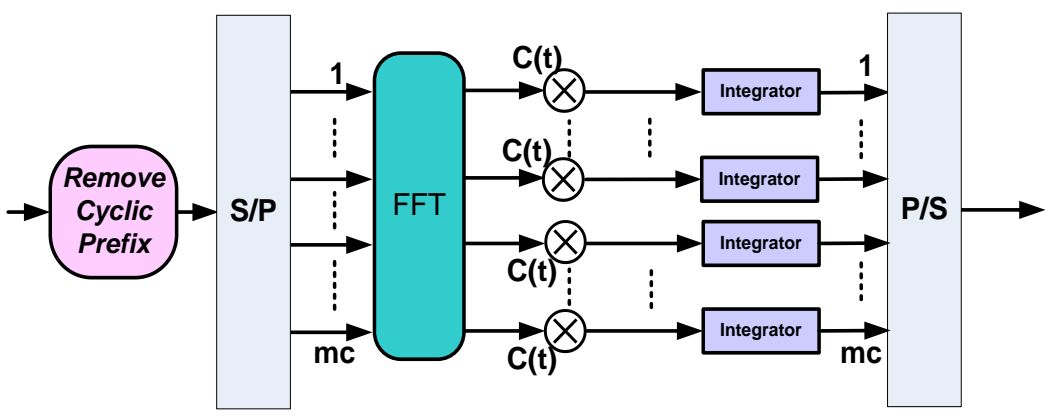

Figure 14 : MC DS CDMA Receiver Model System [7]

In this research, the analyzing focus is the multi user effect to the received signal performance of the multi hop communication system with 2 relays. Multi user model which is designed in this simulation is assumed only the summation of the signal sent from the relays. Relays mean the relays to which different users who send the signals and pass before received by final receiver. Different relays are used here as the worst condition to the performance of the received signal.

Figure 15 shows the model of multi user scheme in multi hop communication with one relay. The multi user model assumes that the communication is in uplink mode, therefore $1^{\text {st }}$ user until $\mathrm{N}^{\text {th }}$ user will generate the random bit and each information will be modulated and transmitted passing the different fading channel to the relay and directly to the receiver. The transmitted signal from every user will pass three fading channels. One signal will be transmitted directly to the receiver, and the second signal will be transmitted to the relay via second fading channel, and 
after received by relay the signal will be received and forward to be transmitted passing the third channel to receiver. The signal in receiver will be acummulated from all users in which every user sends two signal because there are two hops from every users. In the receiver the system will separate the signal from different user by multi user detector using MC CDMA / MC DS CDMA despreading and integrator. The performance of multi user will be calculated from one of the user in the receiver system.

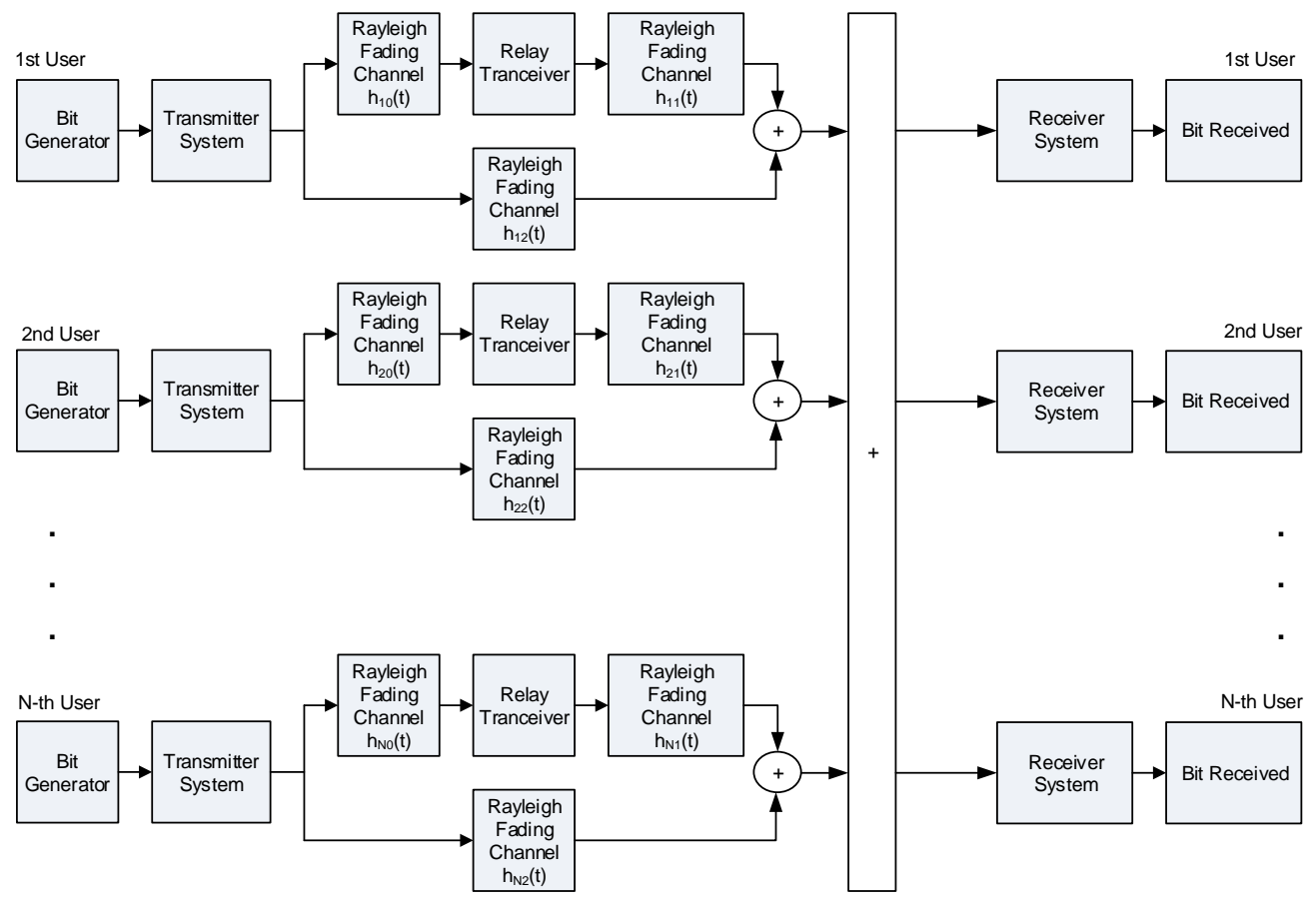

Figure 15 : Multiuser of Multi hop communication with one relay model

\section{MC CDMA MULTIHOP COOPERATIVE SYSTEM PERFORMANCE}

The scenario of running the simulation consist of several analysis, such as :

1. Comparison performance of multi hop MC CDMA and MC DS CDMA in the different mapper.

2. Comparison performance of multi hop MC CDMA and MC DS CDMA in the different scheme of symbol transmission

3. Comparison performance of multi hop Multi user MC CDMA and MC DS CDMA

4. Comparison performance of multi hop MC CDMA and MC DS CDMA on Flat and Freq. Selective Fading

For the first scenario, simulation testing was done with following parameter :

- Flat Fading on Rayleigh Distribution Channel

- 16 spreading code (Walsh-Hadamard)

- MS Velocity $90 \mathrm{~km} / \mathrm{h}$

- QPSK mapper 
- Using 16 subcarriers (at Multicarrier system)

- Perfect Channel Estimation

The simulation result is displayed at figure 16. From the figure it can be concluded that absolutely Marray PSK with the higher Marray will have the worse performance. For MC CDMA in order to reach BER $10^{-4}$ QPSK needs additional power about $2 \mathrm{~dB}$, while for MC DS CDMA QPSK needs additional power about $1 \mathrm{~dB}$. And overall MC DS CDMA has better performance than MC CDMA. In order to reach BER 10-3 at QPSK MC CDMA needs additional power about $5 \mathrm{~dB}$, while at BPSK MC CDMA needs additional power about $3 \mathrm{~dB}$.

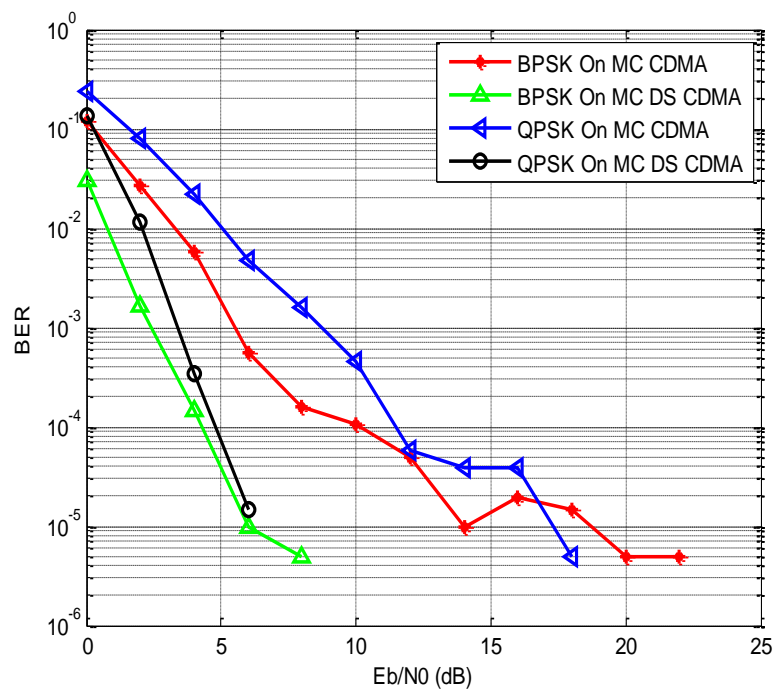

Figure 16 : Multihop Performance On Different Mapper

For the second scenario, simulation testing was done with following parameter :

- Flat Fading on Rayleigh Fading Distribution

- 16 spreading code (Walsh-Hadamard)

- MS Velocity $90 \mathrm{~km} / \mathrm{h}$

- QPSK mapper

- Using 16 subcarriers (At Multicarrier system)

- Perfect Channel Estimation

Second scheme of symbol transmission either on MC DS CDMA or MC CDMA has better performance as showing at the figure 17. For MC CDMA second scheme leads the performance by about $4,5 \mathrm{~dB}$ to reach BER $10^{-3}$. Whereas for MC DS CDMA second scheme leads about 0,5 $\mathrm{dB}$ to reach BER $10^{-3}$. 


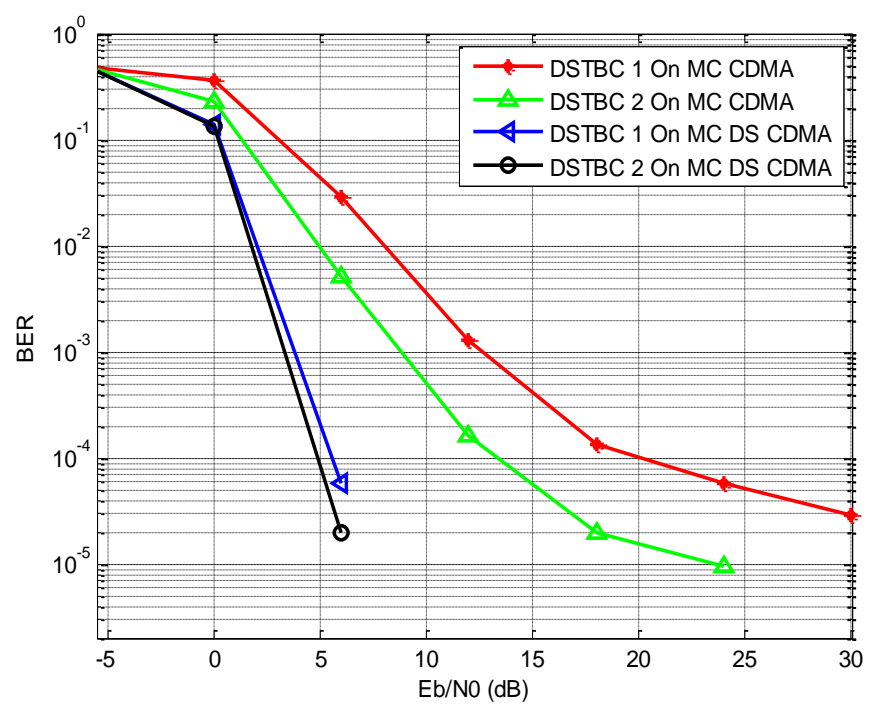

Figure 17 : Multihop MC CDMA and MC DS CDMA Performance Comparison On Different Scheme of Symbol Transmission After Relay

For the third and forth scenario, simulation testing was done with following parameter :

- Flat Fading on Rayleigh Fading Distribution

- 16 spreading code (Walsh-Hadamard)

- MS Velocity $90 \mathrm{~km} / \mathrm{h}$

- QPSK mapper

- Second Scheme of Symbol Transmission

- Number of users : $1,5,10$ and 15 users

- Using 16 subcarriers (At Multicarrier system)

- Perfect Channel Estimation

- MC CDMA and MC DS CDMA

The simulation result is displayed at figure 18 and figure 19. For multi user cases the result of simulation performs similar tendency. At MC CDMA simulation system with 5 users will need much power about $17 \mathrm{~dB}$ than 1 user to reach BER $10^{-3}$. But for 10 users active, system will need only $6 \mathrm{~dB}$ than 5 users. The increase of the active user will increase the needs of power but on decreasing power need tendency. As well as the MC CDMA, MC DS CDMA performs similar result. System with 5 users active needs additional power $14 \mathrm{~dB}$ rather than 1 user. And system with 10 users active needs $6,5 \mathrm{~dB}$ rather than 5 users active. 


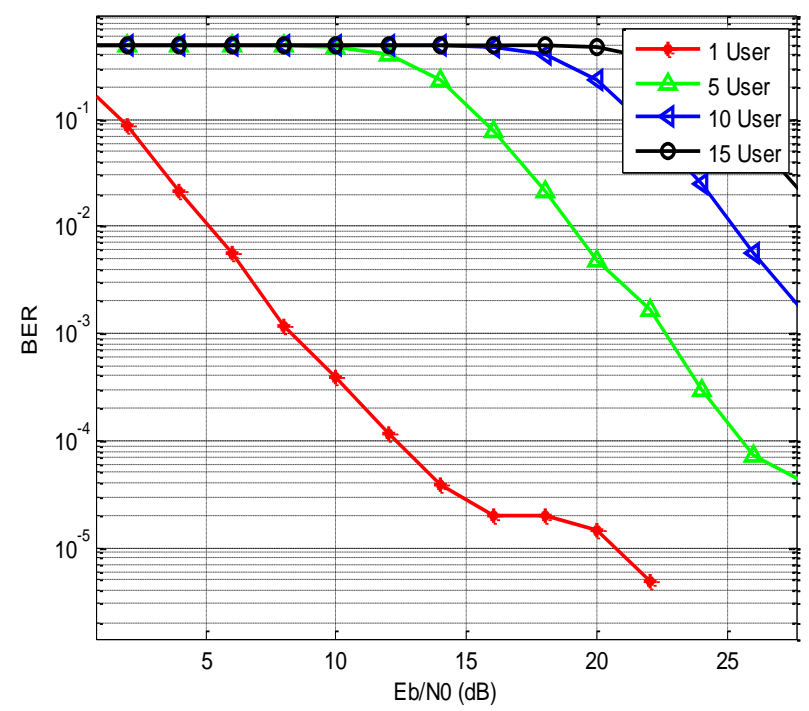

Figure 18 : Multihop on Multiuser MC CDMA Performance

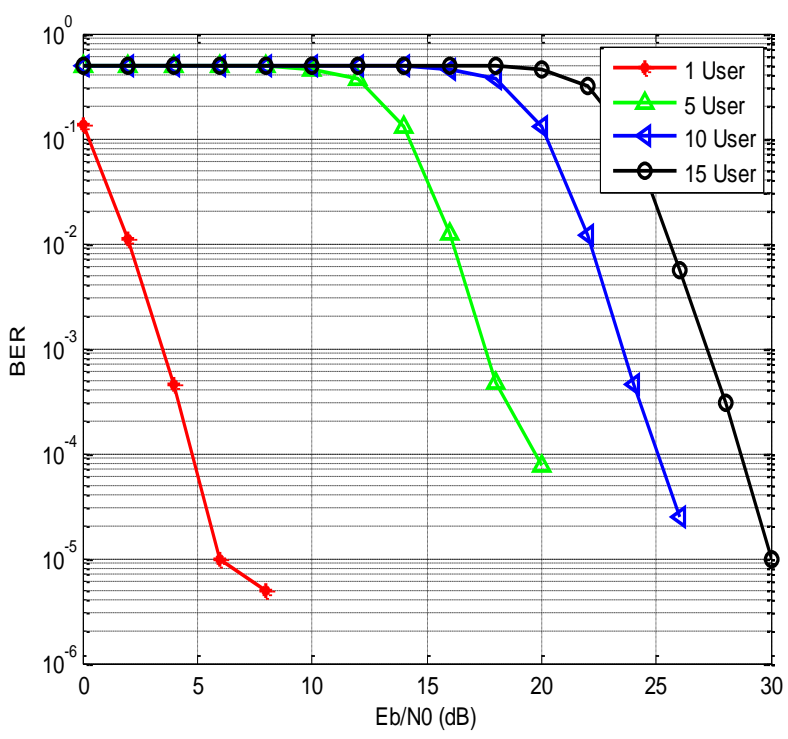

Figure 19 : Multihop on Multiuser MC DS CDMA Performance

For the fifth scenario, simulation testing was done with following parameter :

- Flat and Frequency Selective Fading on Rayleigh Fading Distribution

- 16 spreading code (Walsh-Hadamard)

- MS Velocity $60 \mathrm{~km} / \mathrm{h}$

- BPSK mapper

- Second Scheme of Symbol Transmission

- Using 16 subcarriers (At Multicarrier system)

- Perfect Channel Estimation

- MC CDMA and MC DS CDMA

The simulation also compares the performance of flat fading channel and frequency selective 
channel which is displayed at figure 20. On flat fading MC DS CDMA leads the performance by about $4 \mathrm{~dB}$ power less than the power need of MC CDMA to reach BER $10^{-3}$. But on frequency selective the result is reversed. MC DS CDMA needs much additional power to reach BER $10^{-3}$ than MC CDMA. This means that MC DS CDMA has less strength to face the frequency selective fading situation than MC CDMA. This case happens at the vehicle standard velocity and uses 16 spreading code and 16 subcarriers.

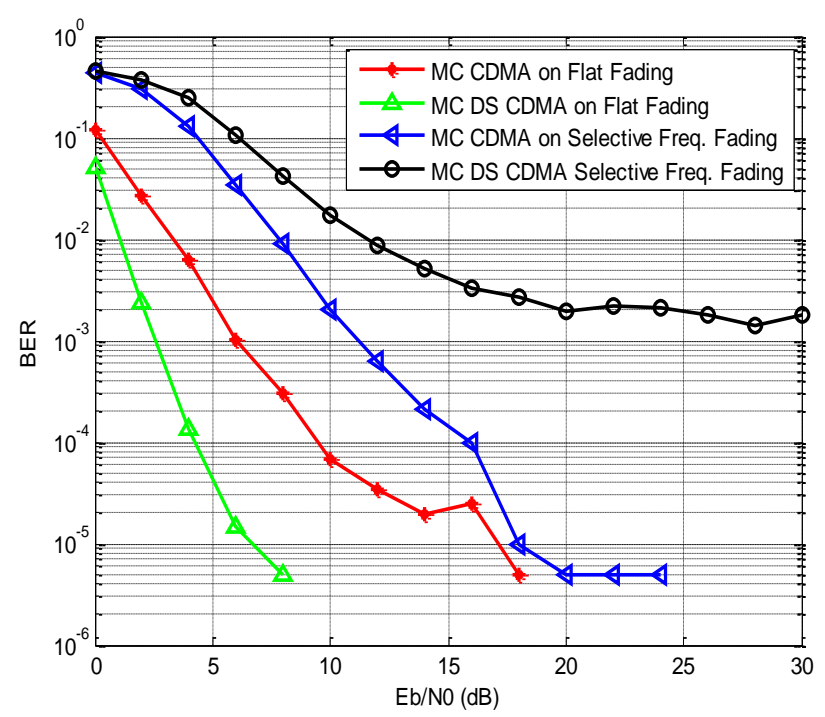

Figure 20 : Performance of Multi hop Communication on Flat and Freq. Selective Fading

\subsection{Conclusion}

1. PSK with the higher Marray will have the worse performance in the multi hop communication either MC CDMA or MC DS CDMA. And MC DS CDMA has better performance than MC CDMA. In order to reach BER 10-3 at QPSK MC CDMA needs additional power about $5 \mathrm{~dB}$, while at BPSK MC CDMA needs additional power about 3 dB.

2. Second scheme of symbol transmission either on MC DS CDMA or MC CDMA has better performance.

3. For multi user cases the result of simulation performs similar tendency. The increase of the active user will increase the needs of power but on decreasing power need tendency.

4. MC DS CDMA has less strength to face the frequency selective fading situation than MC CDMA.

\subsection{Suggestion}

1. There will need an improvement formula on MC DS CDMA and MC CDMA receiver by multi user MAI cancellation to get better performance.

2. Maximum likelihood method to get the binary information will be needed to enhance the performance of multi hop system.

3. Multi antenna scheme at the transmitter and receiver might perform better performance. 


\section{REFERENCES}

[1] Alamouti SM, “A Simple Transmit Diversity Technique for Wireless Communication”, IEEE Journal on Selected Areas in Communication, vol. 16 No.8, October 1998.

[2] Jaafar W., "On the Performance of Distributed-STBC in Multi-hop Wireless Relay Networks", IEEE European Wireless Conference, 2010.

[3] Adi Nugroho,"Analisis Kinerja Sistem Kooperatif Menggunakan Skema Distributed-Alamouti”, Tugas Akhir, ITS, 2010.

[4] Borah D.K, Moreno Crespo, Nammi S., "Distributed Alamouti Transmit Diversity Technique for Co-Operative Communication", Vehicular Technology Conference, 2007. VTC2007-Spring. IEEE 65th, Dublin, 2007.

[5] J. Proakis, "Digital Communications", McGraw Hill, 3rd., 1995.

[6] David Gesbert, Mansoor Shafi, Da-Shan Shiu, Peter J. Smith, Ayman Naguib, "From Theory to Practice : An Overview of MIMO Space-Time Coded Wireless Systems", Tutorial Paper, IEEE Journal On Selected Areas In Communication Vol. 21, No.3 April 2003, Oslo University, Norway.

[7] Gelar Budiman,Suhartono, Rina Pudji Astuti, "Konfigurasi MIMO MC-CDMA Pada Kanal Fading Rayleigh", Jurnal Telekomunikasi IT Telkom Desember 2007 Volume-12 Nomor 2 Hal. 82-88 ISSN : No. 1410-7066, ITTelkom, 2007.

[8] Nur Andini, Ali Muayyadi, Gelar Budiman, "Analisis Performansi WCDMA Diversitas Relay Pada Kanal Fading”, Prosiding Konferensi Nasional ICT-M Politeknik Telkom (KNIP) ISSN : 2088-8252, Bandung, 2011.

[9] Ali Muayyadi, Gelar Budiman, Rina Pudji Astuti, "The performance analysis of multiuser WCDMA systems using D-STBC in Rayleigh fading channel”, Advanced Communication Technology (ICACT), Pages 1213-1216, South Korea, 2014.

\section{Authors}

Gelar Budiman is a lecturer from Electrical Engineering Faculty of Telkom University since 2008. He was graduated from STTTelkom in 2002 as an Electrical Engineering undergraduate student, and same university as Electrical Engineering Master in Telecommunications in 2005. He is an assistant manager of Distance Learning Education

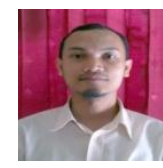
Infrastructure in Telkom University, Bandung, Indonesia and has done several researches and lecturer activities such as eLearning grants and community services in relation of his competency. His research competencies are about wireless communication, signal processing, and mobile application.

Ali Muayyadi is a member of IEEE. He finished his BEng degree in electrical engineering from ITB, Bandung, Indonesia in 1990, MSc degree in mobile communicate ons from ENST, Paris in 1997 and $\mathrm{PhD}$ degree in digital communications from University of Plymouth, UK in 2003. Now he is the head of Telecommunication Transmission Expert

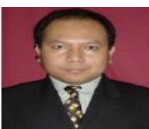
Group of Electrical Engineering Faculty, Telkom University, Bandung, Indonesia.

Rina Pudji Astuti is a lecturer in Electrical Engineering Faculty in Telkom University, Bandung, Indonesia. She finished her undergraduate degree from Electrical Engineering ITS in 1987, Surabaya. She was graduated from Electrical Engineering Master degree from ITB, Bandung, Indonesia in 1999, and Doctoral degree from Electrical and Informatics Engineering in 2009 from ITB. Now she is the Dean of Electrical Engineering Faculty, Telkom university, Bandung, Indonesia. Her interest is in Wireless Communication in speciality of $4 \mathrm{G}$ and $5 \mathrm{G}$ Telecommunication Technology. 